\title{
High Burden of Acquired Morbidity in Survivors of Pediatric Acute Respiratory Distress Syndrome
}

\author{
Sin Wee Loh ${ }^{1}$, Ming Ying Gan², Judith Ju-Ming Wong ${ }^{1}$, Chengsi Ong ${ }^{1}$, Yee Hui Mok ${ }^{1}$, and \\ Jan Hau Lee ${ }^{1}$ \\ ${ }^{1}$ KK Women's and Children's Hospital \\ ${ }^{2}$ National University Singapore Yong Loo Lin School of Medicine
}

March 11, 2021

\begin{abstract}
Introduction: With improving mortality rates in pediatric acute respiratory distress syndrome (PARDS), functional outcomes in survivors are increasingly important. We aim to describe the change in functional status score (FSS) from baseline to discharge and to identify risk factors associated with poor functional outcomes. Methods: We examined clinical records of patients with PARDS admitted to our pediatric intensive care unit (PICU) from 2009 to 2016. Our primary outcome was acquired morbidity at PICU and hospital discharge (defined by an increase in FSS [?]3 points above baseline). We included severity of illness scores and severity of PARDS in our bivariate analysis for risk factors for acquired morbidity. Results: There were 181 patients with PARDS, of which $90(49.7 \%)$ survived. Median pediatric index of mortality 2 score was $4.05(1.22,8.70)$ and $21(26.6 \%)$ patients had severe PARDS. 59 (65.6\%) and 14 (15.6\%) patients had acquired morbidity at PICU and hospital discharge, respectively. Median baseline FSS was $6.00(6.00,6.25)$, which increased to $11.00(8.75,12.00)$ at PICU discharge before decreasing to 7.50 $(6.00,9.25)$ at hospital discharge. All patients had significantly higher median FSS score at both PICU and hospital discharge compared to baseline. Feeding and respiratory were the most affected domains. After adjusting for severity of illness, severity categories of PARDS was not a risk factor for acquired morbidity. Conclusion: Acquired morbidity in respiratory and feeding domains was common in PARDS survivors. Specific attention should be given to these two domains of functional outcomes in these children.
\end{abstract}

\section{Hosted file}

Manuscript MAIN DOCUMENT.pdf available at https://authorea.com/users/400791/articles/513076high-burden-of-acquired-morbidity-in-survivors-of-pediatric-acute-respiratory-distresssyndrome

\section{Hosted file}

Manuscript TABLES.pdf available at https://authorea.com/users/400791/articles/513076-highburden-of-acquired-morbidity-in-survivors-of-pediatric-acute-respiratory-distresssyndrome 